\title{
A Resource Depletion Spiral? A Moderated Mediation Model of Emotional Exhaustion and Venting at Work
}

\author{
Tao Yang \\ Purdue University Fort Wayne \\ Jian-Min Sun \\ The University of Auckland
}

We investigate whether, why, and when emotionally exhausted employees may engage in venting, or discharging negative feelings to others at work. Drawing on emotion regulation research, we envision that emotionally exhausted employees engage in response-focused emotion regulation, which depletes regulatory resources and leads to emotion regulation failures (i.e., venting). We further examine employees' core self-evaluation and turnover intention as boundary conditions for different stages of the mediated relationship. Moderated mediation analysis suggests that emotional exhaustion is positively related to venting only among employees with low core self-evaluation who reluctantly stay in organizations. Implications for research and practice are discussed.

Keywords: Emotional Exhaustion, Venting, Emotion Regulation, Core Self-Evaluation, Turnover Intention

\section{INTRODUCTION}

Venting, or "discharging one's negative feelings by expressing them to others" (Brown, Westbrook, \& Challagalla, 2005, p. 794), has long been construed as one way in which people deal with stressful situations (Carver, Scheier, \& Weintraub, 1989). While "letting off steam" may render some benefits such as temporary emotional relief, venting has largely been viewed as a dysfunctional coping strategy (Day \& Livingstone, 2001; Totterdell \& Parkinson, 1999) and is found to exacerbate the adverse effect of stressors (Brown et al., 2005), impede job performance (e.g., Wang, Liao, Zhan, \& Shi, 2011), and erode social relationships (Côté, 2005).

Despite growing understanding of the deleterious effects of venting, much less is known about who are more likely to "blow off steam" at work. Research suggests that employees who are emotionally exhausted, or "being overextended and depleted of one's emotional and physical resources" (Maslach, Schaufeli, \& Leiter, 2001, p. 399), are likely to discharge their negative feelings at work (Grandey, 2003). Yet, counter to this notion, emotionally drained employees may not actually feel free to vent their feelings (Stickney \& Geddes, 2014), as doing so deviates from the positive emotional display requirements in most jobs and is often discouraged or even sanctioned by organizations.

We reconcile these conflicting views by investigating whether, why and when emotional exhaustion is associated with venting at work. Drawing on emotion regulation literature, we posit that employees who 
are emotionally drained undergo a resource depletion spiral - they engage in response-focused emotion regulation to align with workplace emotional display requirements, which depletes regulatory resources and ultimately leads to regulation failures in the form of venting. Moreover, we contend that the resource loss spiral only holds for certain employees. Drawing on research concerning the role of individual differences in emotion regulation (Grandey \& Gabriel, 2015), we examine whether employees' core selfevaluation impacts the relationship between emotional exhaustion and response-focused emotion regulation. Further, we extend research on the motivations of employees who quit or stay (Hom, Mitchell, Lee, \& Griffeth, 2012) and develop competing explanations that employees' turnover intention can either enhance or inhibit the relationship between response-focused emotion regulation and venting. Figure 1 depicts our moderated mediation model.

\section{FIGURE 1}

\section{HYPOTHESIZED MODEL}

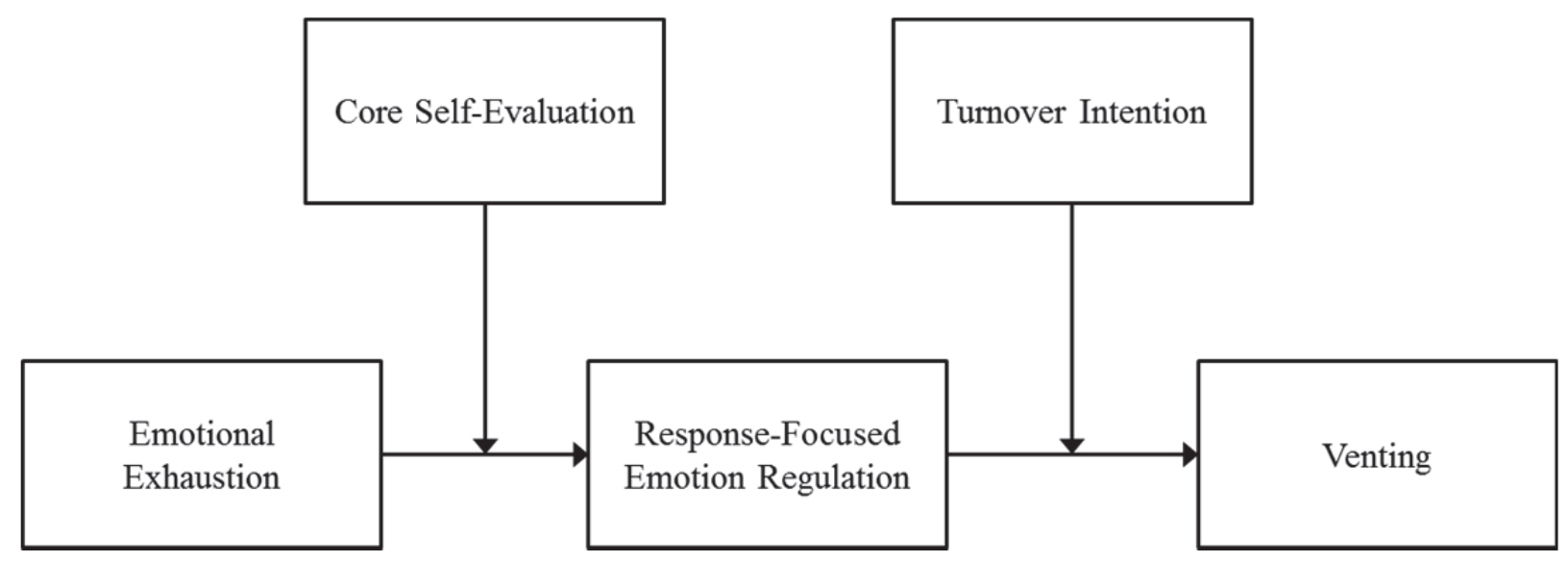

We contribute to the literature in several key ways. We reconcile the conflicting views of whether or not emotionally exhausted employees may discharge their negative feelings at work by examining the emotion regulation mechanism. We advance theory by elucidating a resource depletion spiral through which emotional exhaustion lapses into failures of emotion regulation. Moreover, we contribute to a deeper understanding of employees' psychological characteristics as boundary conditions that either facilitate or inhibit different stages of the resource depletion spiral. Our findings suggest that core selfevaluation enables employees to effectively cope with emotional exhaustion, thereby obviating the need for response-focused emotion regulation. We further unveil employees' turnover intention as a boundary condition under which emotion regulation impairments (i.e., venting) are likely to occur. We provide a strong inference test (Platt, 1964) by articulating competing explanations of the motivations behind employees who quit or stay in their organizations. We therefore shed light on the much-overlooked role of turnover intention in emotion regulation research. Practically, our findings that emotional exhaustion translates into venting only among reluctant stayers with low core self-evaluation provide organizations with important insights in employee selection, retention, and well-being.

\section{THEORY AND HYPOTHESES}

\section{Emotional Exhaustion and Venting: The Emotion Regulation Mechanism}

Job burnout has gone pandemic. The World Health Organization has, for the first time, officially classified burnout as an occupational hazard (Turner, 2019). As a core feature of burnout, emotional exhaustion depicts an employee's emotional weariness and physical fatigue resulting from prolonged stress from work (Maslach \& Jackson, 1981). As emotional drain reflects depleted energy (Hobfoll, 1989) and acts as a threat to one's well-being (Lazarus, 1991), emotionally exhausted employees are likely to 
experience negative emotions. Emotional exhaustion further instigates physiological stress reactions that trigger negative emotional reactions (Melamed, Shirom, Toker, Berliner, \& Shapira, 2006). Research has indeed shown that employees who are emotionally "used up" from work tend to feel a slew of negative emotions such as upset, anxiety, and anger (Maslach \& Jackson, 1984). Yet, in most jobs that require contact with others (e.g., coworkers, supervisors, and customers), expressing positive emotions and suppressing negative emotions are construed as formal job requirements by employees and supervisors alike (Diefendorff, Richard, \& Croyle, 2006). As Diefendorff and Gosserand (2003) posit, the discrepancy between felt negative emotions and the emotional display requirements impels employees to adopt emotion regulation strategies.

The process model of emotion regulation (Gross, 1998) posits that emotion regulation unfolds via two stages. Individuals may engage in antecedent-focused emotion regulation, in which they adjust felt emotions by modifying the situation or the perception thereof. When adjusting felt emotions is not feasible, individuals could employ response-focused emotion regulation to modify emotional expressions (Grandey, 2000). It is reasonable to expect that employees who are emotionally exhausted and thus experience negative feelings are likely to engage in response-focused emotion regulation-faking positive emotions and suppressing negative emotions (Grandey, 2000) - to fulfill workplace emotional display requirements. Echoing this notion, Pugh and colleagues (2011) noted that "emotional exhaustion may lead employees to engage in more surface acting to override their true feelings and display positive emotions" (p. 386). Research has shown that employees who experience emotional exhaustion and negative feelings at work modify their emotional expressions to align with emotional display expectations (e.g., Goldberg \& Grandey, 2007; Keller, Chang, Becker, Goetz, \& Frenzel, 2014; Rupp \& Spencer, 2006).

\section{Hypothesis 1: Emotional exhaustion is positively related to response-focused emotion regulation.}

As Grandey and colleagues (2004) noted, venting occurs "when the individual does not regulate emotions" (emphasis in original, p. 403) and simply lets out negative feelings. In line with the selfregulation perspective, we construe venting as failures to exert self-control over emotional expressions. Although venting contradicts the emotional display requirements in most work settings and is seen as unprofessional or even sanctionable, employees are likely to engage in venting when they fall short of regulatory resources to modify emotional expressions. As individuals can afford only a limited amount of regulatory resources (Muraven \& Baumeister, 2000), we posit that prolonged enactment of responsefocused emotion regulation drains regulatory resources and is associated with a higher likelihood of emotion-regulation failures in the form of letting out negative feelings at work. Consistent with this notion, research has shown that hiding felt negative emotions and faking unfelt positive emotions deplete self-regulatory resources and result in impairments of subsequent self-control (e.g., Gailliot et al., 2007; Vohs \& Heatherton, 2000).

\section{Hypothesis 2: Response-focused emotion regulation is positively related to venting.}

\section{Moderating Effect of Core Self-evaluation}

Our reasoning so far suggests that emotionally exhausted employees are likely to engage in responsefocused emotion regulation, yet we postulate that employees' individual differences may impact the strength of such association. We focus on individual differences in core self-evaluation, defined as "fundamental premises that individuals hold about themselves and their functioning in the world" (Judge, Erez, \& Bono, 1998, p. 168). Core self-evaluation is germane to our argument, as it concerns how individuals navigate stressful conditions (Kammeyer-Mueller, Judge, \& Scott, 2009). Core self-evaluation is a broad personality trait that comprises four narrower traits: self-esteem, generalized self-efficacy, internal locus of control, and emotional stability (Judge, Erez, Bono, \& Thorensen, 2003). Individuals with high core self-evaluation have positive self-regards and "see themselves as capable, worthy, and in control of their lives" (Judge, Van Vianen, \& De Pater, 2004, p. 327). 
Drawing on research concerning core self-evaluation in the stress process (Kammeyer-Mueller et al., 2009), we argue that core self-evaluation allows employees to react to, and cope with, emotional exhaustion in more functional manners and alleviates their felt negative emotions. Specifically, employees with high core self-evaluation are likely to be more resilient to emotional exhaustion; they are confident in their abilities to overcome emotional drain and believe they are in control of replenishing their energies. Further, employees with high core self-evaluation are likely to adopt functional strategies, such as problem solving and seeking social support, to cope with emotional exhaustion (KammeyerMueller et al., 2009) and keep it from escalating into negative emotions. Consistent with this notion, research has shown that individuals with higher core self-evaluation cope with stressors more effectively (Wagstaff, del Carmen Triana, Kim, \& Al-Riyami, 2015). As such, core self-evaluation dilutes or dissipates negative feelings that emotionally exhausted employees would otherwise experience and brings their felt emotions closer to what they are supposed to display at work (Diefendorff \& Gosserand, 2003). Thus, higher core self-evaluation will attenuate the association between emotion exhaustion and responsefocused emotion regulation. In contrast, employees with lower core self-evaluation are likely to be disturbed by emotional exhaustion-lacking confidence and control over resource replenishment and resorting to dysfunctional coping strategies such as avoidance and self-distraction (Kammeyer-Mueller et al., 2009), which elevates negative emotions and necessitates self-regulation of emotional displays. Thus, lower core self-evaluation will strengthen the association between emotional exhaustion and responsefocused emotion regulation.

Hypothesis 3: Core self-evaluation moderates the positive relationship between emotional exhaustion and response-focused emotion regulation such that the relationship is stronger when core self-evaluation is low rather than high.

\section{Moderating Effect of Turnover Intention}

Recent advance in turnover research has offered an in-depth understanding of different motivations behind employees who quit or stay in their organizations. Hom and colleagues (2012) draw on two dimensions - (1) one's desire to stay or leave the organization, and (2) one's high or low perceived volitional control of one's preference, and categorize employees into enthusiastic stayers, reluctant stayers, enthusiastic leavers, and reluctant leavers. As employees with low turnover intention are likely to remain in organizations, the mindsets of enthusiastic stayers and reluctant stayers are particularly germane to our argument. Enthusiastic stayers voluntarily remain in organizations; they want to stay for intrinsic reasons-for example, they tend to see person-job fit, find meaning in their work, and share organizational values and goals (Hom et al., 2012). In contrast, reluctant stayers remain in organizations involuntarily. They have to stay due to external pressure and constraints. For example, they must stay to provide financial support for their families and to avoid losing pensions or disrupting their spouses' careers and children's education.

We posit that the mindsets of enthusiastic stayers and reluctant stayers, albeit antithetical, are both plausible for employees with low turnover intention. Yet they play strikingly different roles in the relationship between response-focused emotion regulation and venting. From the perspective of selfdetermination theory (Deci \& Ryan, 2000), employees with low turnover intention, as enthusiastic stayers, tend to approach work with autonomous motivation - as they identify with organizational values and find the job intrinsically satisfying - and devote greater effort and persistence in goal pursuits (Kristof-Brown, Zimmerman, \& Johnson, 2005). We argue that this logic extends to the context of emotion regulation. Employees who voluntarily stay with low intention to quit are likely to recognize the value of positive emotional displays, identify with emotional expression requirements, and expend more effort in emotion regulation, thereby reducing the likelihood of emotion-regulation failures in the form of venting. Thus, from the view of enthusiastic stayers, low turnover intention will attenuate the association between response-focused emotion regulation and venting.

In contrast, the competing explanation derives from the plausible argument that employees with low turnover intention can be reluctant stayers. In line with self-determination theory (Deci \& Ryan, 2000), 
reluctant stayers tend to approach work with controlled motivation - as they stay involuntarily for extrinsic reasons to avoid financial losses or feeling guilty about disrupting family members' lives (Johnson, Chang, \& Yang, 2010) - and exert minimum effort in goal pursuits (Luchak \& Gellatly, 2007). In the context of emotion regulation, those who reluctantly stay are likely to devalue and dismiss emotional expression requirements as a nuisance, and spend minimum effort in emotion regulation, thereby increasing the likelihood of emotion-regulation failures (i.e., venting). Research has shown that controlled motivation, but not autonomous motivation, depletes self-regulatory resources (Moller, \& Deci, \& Ryan, 2006). Thus, from the view of reluctant stayers, low turnover intention will strengthen the association between response-focused emotion regulation and venting.

We predict the following competing hypotheses:

Hypothesis 4a: According to the enthusiastic-stayer view, the positive relationship between responsefocused emotion regulation and venting will be weaker when turnover intention is low.

Hypothesis 4b: According to the reluctant-stayer view, the positive relationship between responsefocused emotion regulation and venting will be stronger when turnover intention is low.

Integrating the preceding hypotheses, we propose a moderated mediation model in which responsefocused emotion regulation mediates the relationship between emotional exhaustion and venting. The first-stage of the mediation (i.e., emotional exhaustion $\rightarrow$ response-focused emotion regulation) is moderated by core self-evaluation and the second-stage of the mediation (i.e., response-focused emotion regulation $\rightarrow$ venting) is moderated by turnover intention. In line with the preceding arguments of the enthusiastic- vs. reluctant-stayer views regarding turnover intention, we predict the following competing hypotheses:

Hypothesis 5a: According to the enthusiastic-stayer view, the mediated relationship between emotional exhaustion and venting (via response-focused emotion regulation) will be strongest when core selfevaluation is low and turnover intention is high.

Hypothesis 5b: According to the reluctant-stayer view, the mediated relationship between emotional exhaustion and venting (via response-focused emotion regulation) will be strongest when core selfevaluation is low and turnover intention is low.

\section{METHOD}

\section{Participants and Procedure}

We invited working adults in heterogeneous organizations in China to participate in a survey. A total of 205 individuals were invited and directly returned their finished surveys to us. All participants were ensured their participation was voluntary and anonymous. We removed 23 participants who provided incomplete information for study variables. The final sample included 182 participants working in customer service (17\%), sales (35\%), administrative (24\%), and technical (24\%) positions. Participants had frequent interactions with others (e.g., coworkers, supervisors, customers) on a typical workday. The majority of participants were male $(57.7 \%)$ and had college degrees or higher $(64.8 \%)$. On average, participants were 31.1 years-old $(S D=8.4)$ and worked 4.7 years $(S D=5.8)$ in their organizations.

\section{Measures}

Unless otherwise noted, all measures were translated from English into Chinese following the translation and back-translation procedures (Brislin, 1980). 


\section{Emotional Exhaustion}

We measured emotional exhaustion with the six-item Job-Related Exhaustion Scale (Wharton, 1993). Sample items were "I feel emotionally drained from my work" and "I feel burned out from my job" $(1=$ never to $5=$ always; $\alpha=.86$ ).

\section{Core Self-evaluation}

We used the 12-item Core Self-Evaluations Scale (Judge et al., 2003). A sample item was "Overall, I am satisfied with myself" $(1=$ strongly disagree to $5=$ strongly agree; $\alpha=.70)$.

\section{Response-focused Emotion Regulation}

We used the seven-item scale from Grandey, Fisk, and Steiner (2005) based on Grandey (2003) and Brotheridge and Lee (2003). Participants indicated how often they engaged in each behavior when interacting with others at work. Sample items were "I fake a good mood" and "I hide my true feelings about situations" $(1=$ never to $5=$ always; $\alpha=.84)$.

\section{Turnover Intention}

We used the four-item scale originally developed in the Chinese context (Farh, Tsui, Xin, \& Cheng, 1998). A sample item was "I often think of quitting my present job" $(1=$ strongly disagree to $6=$ strongly agree; $\alpha=.86)$.

\section{Venting}

We measured venting with two items from Grandey et al. (2004). Participants indicated how often they engaged in these behaviors when interacting with others at work. The items were "I let my feelings out somehow," and "I expressed anger to the person(s) who caused the problem" $(1=$ never to $5=$ always; $\alpha=.60)$. Although the internal consistency reliability is comparable to other venting measures (e.g., $\alpha=.60$; Brown et al., 2005), it is below the recommended level (Nunnally, 1978). Attenuation of measurement reliability is more likely to produce Type II than Type I error, yielding conservative estimates of the relationship strength. (Brown et al., 2005).

\section{Control Variables}

We controlled for a range of variables associated with emotional exhaustion and emotion regulation. We controlled for demographic variables of age, gender, and organizational tenure (e.g., Dahling \& Perez, 2010; Johnson \& Spector, 2007; Scott \& Barnes, 2011; Wharton, 1993), as well as the dispositional variable of negative affectivity (Kammeyer-Mueller et al., 2013) measured with the 10-item subscale ( $\alpha$ $=.83$ ) of the Positive and Negative Affect Schedule (Watson, Clark, \& Tellegen, 1988; e.g., "upset," "distressed," "nervous;" 1 = never to 5 = always). Because our sample was from China, we controlled for individual differences in collectivism using the 15-item psychological collectivism scale $(\alpha=.74)$ from Jackson, Colquitt, Wesson, and Zapata-Phelan (2006). Sample items were "I care about the well-being of groups," and "I follow the norms of groups" $(1=$ strongly disagree to $5=$ strongly agree). Moreover, we controlled for perceived job demands in terms of (1) positive display rules, measured with one item adapted from Grandey (2003), "Part of my job is to make others (e.g., customers, coworkers, and supervisors) feel good" ( 1 = strongly disagree to $6=$ strongly agree $)$, and (2) duration of interaction with others, measured with two items $(\alpha=.74$; e.g., "I have to spend a lot of time with each person I work with") based on Morris and Feldman (1997).

\section{Analytic Strategy}

Our hypothesized model was a moderated mediation model in which core self-evaluation moderated the first-stage path from the independent variable (emotional exhaustion) to the mediator (responsefocused emotion regulation), and turnover intention moderated the second-stage path from the mediator to the dependent variable (venting). We ran a series of regressions in a path analytic approach recommended by Edwards and Lambert (2007), using Mplus 7.11 (Muthén \& Muthén, 2012). All variables (except 
gender) were mean centered before generating interaction terms. We used likelihood ratio tests to compare model fit (Snijders \& Bosker, 1999). We computed indirect effects by multiplying the first- and second-stage path estimates at high and low levels of the moderators. Because the indirect effects did not follow a normal distribution, we obtained $95 \%$ confidence intervals of the indirect effects using 20,000 bootstraps (Selig \& Preacher, 2008).

\section{RESULTS}

\section{Confirmatory Factor Analysis and Common Method Bias}

We conducted confirmatory factor analysis to validate the factor structure of focal constructs. In light of our sample size, we used item parceling to generate indicators of each construct (Little, Cunningham, Shahar, \& Widaman, 2002): emotional exhaustion (3 indicators), core self-evaluation (4 indicators), response-focused emotion regulation ( 2 indicators), and turnover intention (2 indicators). Venting was indicated by its two items without parceling. The five-factor model showed an acceptable fit $\left(\chi^{2}[56]=\right.$ 75.47, root-mean-square error of approximation [RMSEA] $=.04$, comparative fit index $[\mathrm{CFI}]=.97$, Tucker-Lewis index $[\mathrm{TLI}]=.96$, standardized root-mean-square residual $[\mathrm{SRMR}]=.04$ ) and a better fit than a one-factor model $\left(\chi^{2}[65]=368.01\right.$, RMSEA $=.16$, CFI $=.59$, TLI $=.50$, SRMR $=.11 ; \Delta \chi^{2}[9]=$ $292.54, p<.01)$, supporting discriminant validity of the focal constructs.

Because we assessed focal constructs from a single source, common method bias might be possible. We followed the recommendations of Podsakoff, MacKenzie, Lee, and Podsakoff (2003) and ran Harman's one-factor test by subjecting indicators of the focal constructs to an exploratory factor analysis. We found no evidence for a single dominant factor; the factor with the highest eigenvalue accounted for a relatively small portion $(29.9 \%)$ of covariance among indicators, suggesting a single method factor did not fully underlie our data. Importantly, common method bias does not produce spurious interaction effects (Siemsen, Roth, \& Oliveira, 2010), which are central to our study.

\section{Hypotheses Testing}

Table 1 shows the descriptive statistics and correlations of study variables. The pattern of correlations among focal variables is consistent with past research (e.g., Hülsheger \& Schewe, 2011; KammeyerMueller et al., 2013). As Table 2, Model 1 shows, emotional exhaustion is not a significant predictor of response-focused emotion exhaustion $(b=.10, n s)$, not supporting Hypothesis 1. As Table 2, Model 4 shows, response-focused emotion regulation is not a significant predictor of venting $(b=.12, n s)$, not supporting Hypothesis 2.

\section{TABLE 1 DESCRIPTIVE STATISTICS AND CORRELATIONS}

\begin{tabular}{|c|c|c|c|c|c|c|c|c|c|c|c|c|c|c|c|}
\hline & Variables & $M$ & $S D$ & 1 & 2 & 3 & 4 & 5 & 6 & 7 & 8 & 9 & 10 & 11 & 12 \\
\hline 1. & Age & 31.15 & 8.42 & & & & & & & & & & & & \\
\hline 2. & Gender & 0.42 & 0.50 & .05 & & & & & & & & & & & \\
\hline 3. & Organizational tenure & 4.68 & 5.78 & .64 & -.04 & & & & & & & & & & \\
\hline 4. & Negative affectivity & 2.04 & 0.54 & -.06 & -.00 & -.13 & $(.83)$ & & & & & & & & \\
\hline 5 . & Collectivism & 3.90 & 0.60 & .18 & -.02 & .19 & -.21 & $(.74)$ & & & & & & & \\
\hline 6. & Positive display rule & 4.04 & 1.51 & .07 & .07 & -.01 & -.04 & .24 & & & & & & & \\
\hline 7. & Duration of interaction & 4.07 & 1.30 & -.00 & .02 & -.03 & .03 & .08 & .31 & $(.74)$ & & & & & \\
\hline 8. & Emotional exhaustion & 2.25 & 0.82 & -.03 & -.04 & .05 & .48 & -.18 & -.03 & .19 & $(.86)$ & & & & \\
\hline 9. & Core self-evaluation & 3.53 & 0.50 & .03 & .07 & .01 & -.28 & .29 & .08 & .05 & -.32 & $(.70)$ & & & \\
\hline & $\begin{array}{l}\text { Response-focused } \\
\text { emotion regulation }\end{array}$ & 2.16 & 0.73 & -.24 & -.10 & -.19 & .35 & -.22 & -.10 & .15 & .31 & -.23 & (.84) & & \\
\hline & Turnover intention & 2.58 & 1.27 & -.29 & .03 & -.32 & .36 & -.34 & -.15 & .02 & .36 & -.27 & .21 & $(.86)$ & \\
\hline 12. & Venting & 2.38 & 0.79 & -.07 & -.14 & -.02 & .20 & -.03 & .04 & .05 & .24 & -.16 & .20 & .13 & $(.60)$ \\
\hline
\end{tabular}

Note. $N=182$. Gender: $1=$ female, $0=$ male. Organizational tenure in years. Internal consistency reliabilities are on the diagonal in the parentheses. Correlations $\geq .15$ or $\leq-.15$ are significant at $p<.05$ (two-tailed tests). 
TABLE 2

UNSTANDARDIZED REGRESSION ESTIMATES

\begin{tabular}{|c|c|c|c|c|c|}
\hline \multirow[b]{2}{*}{ Variables } & \multicolumn{2}{|c|}{$\begin{array}{l}\text { Response-Focused } \\
\text { Emotion Regulation }\end{array}$} & \multicolumn{3}{|c|}{ Venting } \\
\hline & Model 1 & Model 2 & Model 3 & Model 4 & Model 5 \\
\hline Intercept & $2.22(.06)^{* * *}$ & $2.19(.06)^{* * *}$ & $2.46(.07)^{* * *}$ & $2.46(.07)^{* * *}$ & $2.49(.07)^{* * *}$ \\
\hline Age & $-.02(.01)^{*}$ & $-.01(.01)$ & $-.01(.01)$ & $-.00(.01)$ & $-.00(.01)$ \\
\hline Gender & $-.12(.10)$ & $-.12(.10)$ & $-.21(.11)$ & $-.20(.11)$ & $-.21(.11)$ \\
\hline Organizational tenure & $-.01(.01)$ & $-.01(.01)$ & $.00(.01)$ & $.00(.01)$ & $.01(.01)$ \\
\hline Negative affectivity & $.31(.10)^{* *}$ & $.31(.10)^{* *}$ & $.17(.12)$ & $.12(.13)$ & $.12(.12)$ \\
\hline Collectivism & $-.10(.09)$ & $-.10(.09)$ & $.05(.10)$ & $.07(.11)$ & $.09(.10)$ \\
\hline Positive display rule & $-.04(.03)$ & $-.04(.03)$ & $.03(.04)$ & $.04(.04)$ & $.05(.04)$ \\
\hline Duration of interaction & $.09(.04)^{*}$ & $.09(.04)^{*}$ & $.00(.05)$ & $-.01(.05)$ & $-.03(.05)$ \\
\hline Emotional exhaustion & $.10(.07)$ & $.08(.07)$ & $.15(.08)$ & $.13(.09)$ & $.14(.08)$ \\
\hline Core self-evaluation & $-.14(.11)$ & $-.12(.11)$ & $-.13(.12)$ & $-.11(.13)$ & $-.14(.12)$ \\
\hline Emotional exhaustion $\times$ Core self-evaluation & & $-.23(.11)^{*}$ & & & \\
\hline Response-focused emotion regulation & & & & $.12(.09)$ & $.15(.09)$ \\
\hline Turnover intention & & & & $.02(.05)$ & $.04(.05)$ \\
\hline Response-focused emotion regulation $\times$ & & & & & $-.13(.06)^{*}$ \\
\hline Turnover intention & $25 * * *$ & $26 * * *$ & & & $13 * *$ \\
\hline $\begin{array}{l}R^{2} \\
\Delta R^{2}\end{array}$ & $.25 * * *$ & $.261 *$ & $.10^{*}$ & $.11^{*}$ & $\begin{array}{l}.13 * \pi \\
.02 *\end{array}$ \\
\hline Likelihood ratio $(d f)$ & $51.21(9)^{* * *}$ & $4.22(1)^{*}$ & $18.64(9)^{*}$ & $1.97(2)$ & $5.29(1)^{*}$ \\
\hline
\end{tabular}

Note. $N=182$. Unstandardized estimates (standard errors) are reported. Gender: $1=$ female, $0=$ male.

$* p<.05 * * p<.01 * * * p<.001$ (two-tailed tests).

Hypothesis 3 predicts that the positive relationship between emotional exhaustion and responsefocused emotion regulation is stronger when core self-evaluation is lower. As Table 2, Model 2 shows, emotional exhaustion $\times$ core self-evaluation is significant $(b=-.23, p<.05)$. Simple slope tests (Aiken \& West, 1991) show that emotional exhaustion is positively related to response-focused emotion regulation when core self-evaluation is low $(-1 S D$; simple slope $=.19, p<.05)$ but not when it is high $(+1 S D$; simple slope $=-.04, n s)$. Figure 2 depicts the interaction. Thus, Hypothesis 3 is supported. 


\section{FIGURE 2}

THE RELATIONSHIP BETWEEN EMOTIONAL EXHAUSTION AND RESPONSE-FOCUSED EMOTION REGULATION AT LOW AND HIGH LEVELS OF CORE SELF-EVALUATION

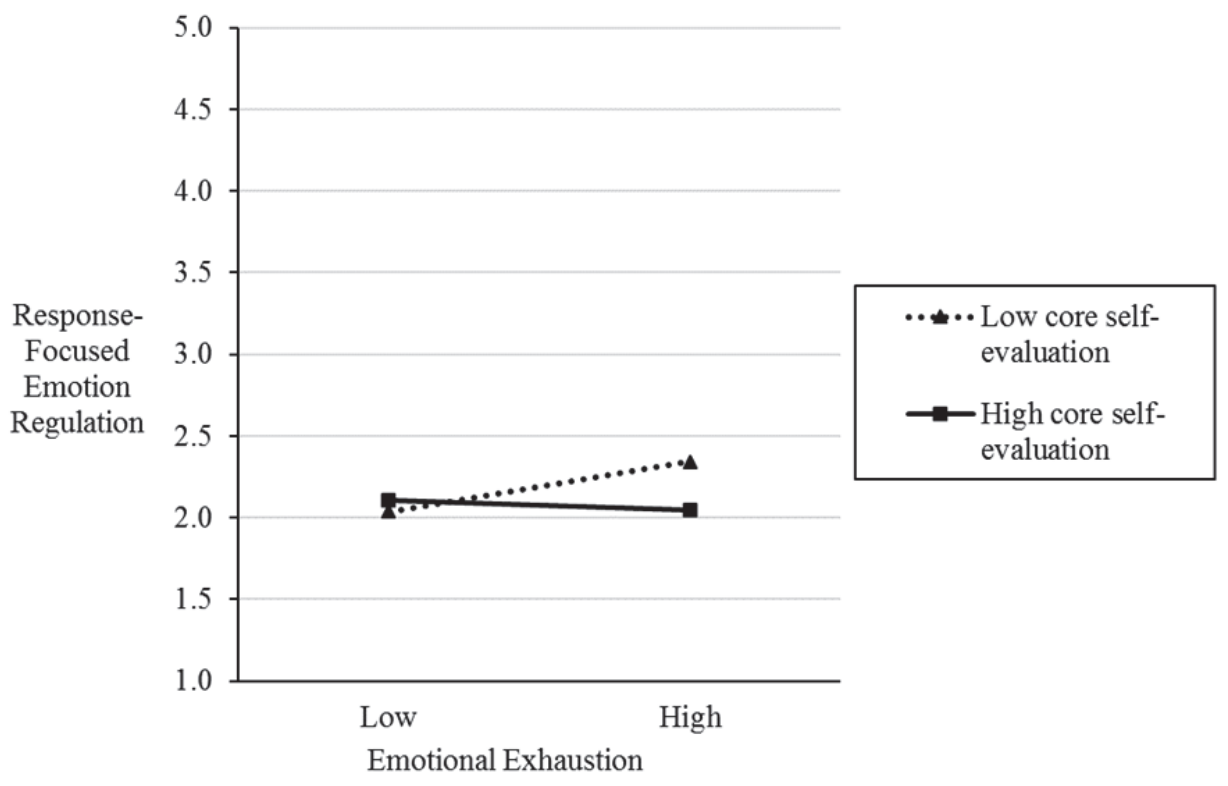

Hypotheses $4 \mathrm{a}$ and $4 \mathrm{~b}$ predict that the positive relationship between response-focused emotion regulation and venting is either inhibited or enhanced by turnover intention. As Table 2, Model 5 shows, response-focused emotion regulation $\times$ turnover intention is significant $(b=-.13, p<.05)$. Simple slope tests show that response-focused emotion regulation is positively relate to venting when turnover intention is low $(-1 S D$; simple slope $=.31, p<.05)$ but not when it is high $(+1 S D$; simple slope $=-.02$, $n s)$. Figure 3 depicts the interaction. Thus, results support Hypothesis 4b, but not Hypothesis 4a. 
FIGURE 3

THE RELATIONSHIP BETWEEN RESPONSE-FOCUSED EMOTION REGULATION AND VENTING AT LOW AND HIGH LEVELS OF TURNOVER INTENTION

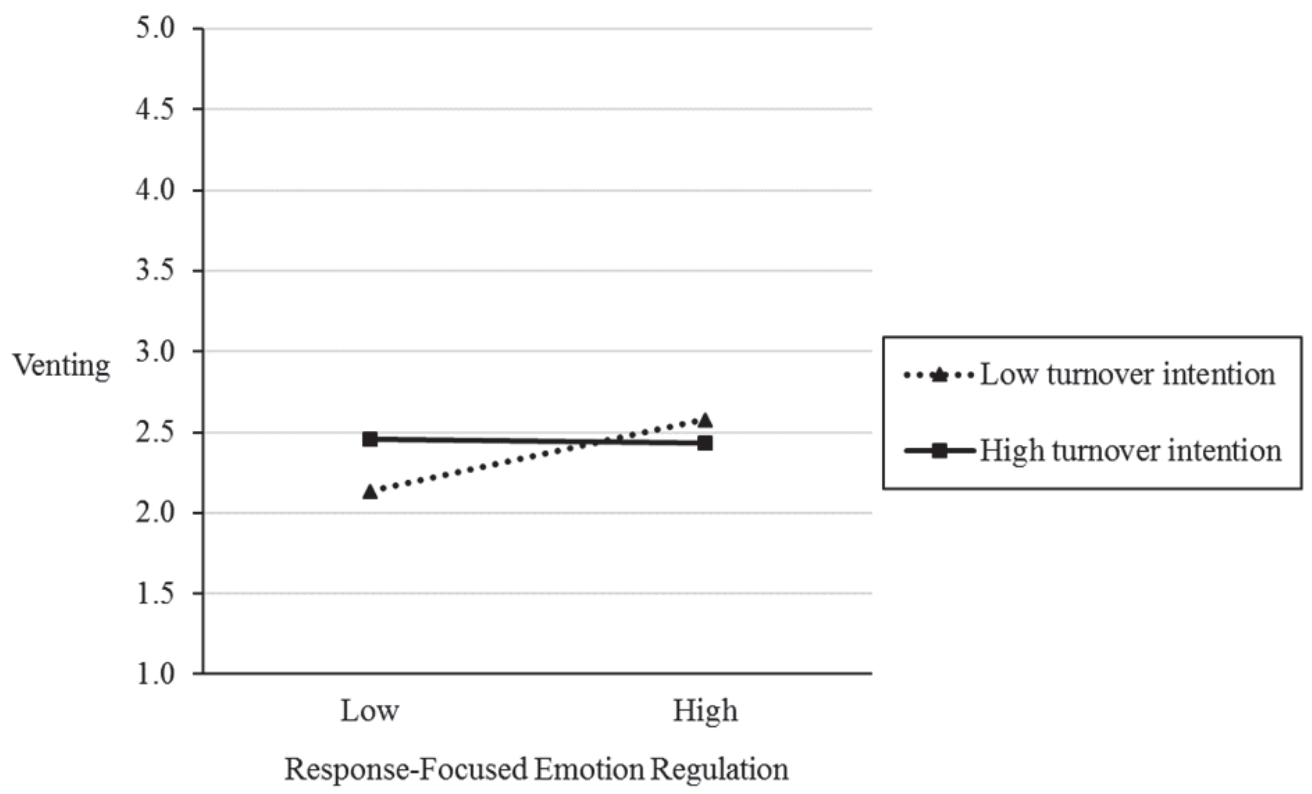

Hypotheses $5 \mathrm{a}$ and $5 \mathrm{~b}$ predict that the mediated relationship between emotional exhaustion and venting is moderated by core self-evaluation and turnover intention. As Table 3 shows, the indirect effect is significant and positive (estimate $=.06,95 \% \mathrm{CI}[.01, .14]$ ) at low levels of core self-evaluation and turnover intention, whereas the indirect effect is not significant at other combinations: (1) low core selfevaluation and high turnover intention (estimate $=-.00,95 \% \mathrm{CI}[-.05, .04]),(2)$ high core self-evaluation and low turnover intention (estimate $=-.01,95 \%$ CI $[-.08, .05]$ ), and (3) high core self-evaluation and high turnover intention (estimate $=.00,95 \%$ CI $[-.02, .03]$ ). Thus, results support Hypothesis $5 \mathrm{~b}$, but not Hypothesis 5a.

TABLE 3

INDIRECT EFFECT VIA RESPONSE-FOCUSED EMOTION REGULATION AT LOW AND HIGH LEVELS OF THE MODERATORS

\begin{tabular}{clccc}
\hline Path $a$ moderator & Path $b$ moderator & Path $a(S E)$ & Path $b(S E)$ & $\begin{array}{c}\text { Indirect effect } \\
{[95 \% \text { CI] }}\end{array}$ \\
\hline Low core self-evaluation & Low turnover intention & $.19(.08)^{*}$ & $.31(.12)^{*}$ & $.06^{*}[.01, .14]$ \\
& High turnover intention & $.19(.08)^{*}$ & $-.02(.10)$ & $-.00[-.05, .04]$ \\
High core self-evaluation & Low turnover intention & $-.04(.10)$ & $.31(.12)^{*}$ & $-.01[-.08, .05]$ \\
& High turnover intention & $-.04(.10)$ & $-.02(.10)$ & $.00[-.02, .03]$ \\
\hline
\end{tabular}

Note. $N=182$. Path $a$ refers to the path from the independent variable (emotional exhaustion) to the mediator (response-focused emotion regulation). Path $b$ refers to the path from the mediator to the dependent variable (venting). The $95 \%$ confidence intervals of indirect effects are based on 20,000 bootstrapped Monte Carlo replications. $* p<.05$ (two-tailed tests). 


\section{Supplemental Analysis}

We examine alternative models in which turnover intention moderates the first-stage path and core self-evaluation moderates the second-stage path. Neither moderation is significant, lending more confidence that the moderators operate in accordance with our theoretical predictions.

\section{DISCUSSION}

\section{Theoretical Implications}

We integrate emotion regulation literature with core self-evaluation research and self-determination theory to develop and test a moderated mediation model of the relationship between emotional exhaustion and venting at work. While organizational scholars have predominantly considered emotional exhaustion as an important work-related outcome, much less attention has focused on the downstream consequences of emotional exhaustion. We investigate whether, why, and when emotionally exhausted employees may engage in venting at work. We contend that emotionally drained employees undertake response-focused emotion regulation to suppress felt negative emotions and fake positive emotions, which depletes regulatory resources and ultimately results in emotion-regulation failures (i.e., venting). Our reasoning echoes Kammeyer-Mueller, Simon, and Judge's (2016) assertion of "a vicious cycle of exhaustion" (p. 578) where the onset of emotional drain spirals into further resource losses.

We reveal response-focused emotion regulation as a mechanism underlying the effect of emotional exhaustion. Though the association between emotional exhaustion and emotion regulation has been well established, the prevailing view construes emotional exhaustion as a consequence of emotion regulation (e.g., Hülsheger \& Schewe, 2011). We extend the literature and posit emotion exhaustion as an antecedent of emotion regulation to the extent that the negative emotions stemming from exhaustion deviate from positive emotional expressions required by most jobs (Diefendorff et al., 2006). Nonetheless, readers should use caution in generalizing our findings to certain jobs that require the display of neutral (e.g., physician) or negative emotions (e.g., bill collector). Future research may examine the attitudes and behaviors of emotionally drained employees across broader job contexts.

Our findings highlight that the resource drain spiral of emotional exhaustion may not always unfold. We unveil important boundary conditions that qualify the relationship between emotional exhaustion and venting. We show that high core self-evaluation weakens the relationship between emotional exhaustion and response-focused emotion regulation, suggesting that individual differences in positive self-regard provide personal resources to compensate for emotional drain. Moreover, we show that low turnover intention strengthens the relationship between response-focused emotion regulation and venting, suggesting that reluctant stayers who remain in organizations for extrinsic reasons (e.g., avoiding disruptions to families or financial losses) are susceptible to emotion-regulation failures. By elucidating competing explanations of distinct motivations (autonomous vs. controlled motivation) behind employees who intend to stay, we provide a strong inference test of the moderating role of turnover intention. Taken together, we find that emotionally drained employees fall in victim of emotion-regulation failures only when they have low core self-evaluation and low turnover intention. We thus provide more theoretical precision in understanding when emotional exhaustion is more detrimental.

\section{Practical Implications}

Our study informs practice in key ways. First, while emotionally exhausted employees may rely on response-focused emotion regulation to manage their emotional expressions, those who see themselves in a positive light are more confident in, and capable of, coping with emotional drain. From a human resource management perspective, organizations should consider personality assessment as part of the selection process and bring on board individuals whose core self-evaluation scores are above certain threshold. Second, although employee retention is a crucial initiative in many organizations, employees who stay can be vulnerable to emotion regulation failures to the extent that they feel compelled to remain for extrinsic reasons. Organizations thus face the challenge of discerning enthusiastic stayers from reluctant stayers. Managers may glean more information about employees' work motivation through 
observations and regular conversations with employees. Moreover, because enacting response-focused emotion regulation can be resource depleting, organizations may provide training for employees to cope with emotional exhaustion. For example, interspersing brief mindfulness exercises during a workday-in which employees pay attention to the present moment without judgment — is salutary in relieving stress and exhaustion (e.g., Glomb, Duffy, Bono, \& Yang, 2011). Trainings that allow employees to focus and reflect on positive (aspects of) events are also feasible avenues to alleviate emotional exhaustion (Bono, Glomb, Shen, Kim, \& Koch, 2013; Grandey, 2000).

\section{Limitations and Future Research}

Although our study has strengths in terms of testing of mechanism and boundary conditions and generalizability across job contexts, it is not without limitations. While the observed directional relationships are in line with theory, the cross-sectional design does not permit causal inferences. Future research adopting experimental designs and time-lagged measures would provide more confidence in causality. Moreover, we provide a strong inference test for the moderating role of turnover intention by articulating competing explanations, yet we do not explicitly measure employees' motivation. Those who remain in organizations are likely driven by a combination of intrinsic and extrinsic reasons, and future research may examine how different motivations operate in tandem to impact employees' emotion regulation at work. Additionally, we assess venting with a short but valid measure, yet the subpar reliability yields conservative estimates of relationships. Future research using an expanded set of items for venting would improve measurement properties.

\section{CONCLUSION}

We investigate whether, why, and when emotionally exhausted employees may fail to regulate their emotional expressions at work. Integrating different lines of research on emotion regulation, core selfevaluation, and turnover, as well as self-determination theory, we envision that employees who are emotionally exhausted undergo a resource depletion spiral and ultimately "let off steam" at work. Yet this relationship only holds for reluctant stayers with low core self-evaluation. Our findings highlight the emotion-regulation challenge faced by emotionally drained employees, and the safeguarding role of individual disposition and motivation against the resource depletion spiral. 


\section{REFERENCES}

Aiken, L. S., \& West, S. G. (1991). Multiple regression: Testing and interpreting interactions. Thousand Oaks, CA: Sage.

Bono, J. E., Glomb, T. M., Shen, W., Kim, E., \& Koch, A. J. (2013). Building positive resources: Effects of positive events and positive reflection on work stress and health. Academy of Management Journal, 56, 1601-1627.

Brislin, R. W. (1980). Translation and content analysis of oral and written materials. In H. Triandis \& J. W. Berry (Eds.), Handbook of cross-cultural psychology (pp. 389-444). Boston: Allyn \& Bacon.

Brotheridge, C., \& Lee, R. T. (2003). Development and validation of the Emotional Labour Scale. Journal of Occupational and Organizational Psychology, 76, 365-379.

Brown, S. P., Westbrook, R. A., \& Challagalla, G. (2005). Good cope, bad cope: Adaptive and maladaptive coping strategies following a critical negative work event. Journal of Applied Psychology, 90, 792-798.

Carver, C. S., Scheier, M. F., \& Weintraub, J. K. (1989). Assessing coping strategies: A theoretically based approach. Journal of Personality and Social Psychology, 56, 267-283.

Côté, S. (2005). A social interaction model of the effects of emotion regulation on work strain. Academy of Management Review, 30, 509-530.

Dahling, J. J., \& Perez, L. A. (2010). Older worker, different actor? Linking age and emotional labor strategies. Personality and Individual Differences, 48, 574-578.

Day, A. L., \& Livingstone, H. A. (2001). Chronic and acute stressors among military personnel: Do coping styles buffer their negative impact on health? Journal of Occupational Health Psychology, 6, 348-360.

Deci, E. L., \& Ryan, R. M. (2000). The "what" and "why" of goal pursuits: Human needs and the selfdetermination of behavior. Psychological Inquiry, 11, 227-268.

Diefendorff, J. M., \& Gosserand, R. H. (2003). Understanding the emotional labor process: A control theory perspective. Journal of Organizational Behavior, 24, 945-959.

Diefendorff, J. M., Richard, E. M., \& Croyle, M. H. (2006). Are emotional display rules formal job requirements? Examination of employee and supervisor perceptions. Journal of Occupational and Organizational Psychology, 79, 273-298.

Edwards, J. R., \& Lambert, L. S. (2007). Methods for integrating moderation and mediation: A general analytical framework using moderated path analysis. Psychological Methods, 12, 1-22.

Farh, J., Tsui, A. S., Xin, K., \& Cheng, B. (1998). The influence of relational demography and guanxi: The Chinese case. Organization Science, 9, 471-488.

Gailliot, M. T., Baumeister, R. F., DeWall, C. N., Maner, J. K., Plant, E. A., Tice, D. M., ... Schmeichel, B. J. (2007). Self-control relies on glucose as a limited energy source: Willpower is more than a metaphor. Journal of Personality and Social Psychology, 92, 325-336.

Glomb, T. M., Duffy, M. K., Bono, J. E., \& Yang, T. (2011). Mindfulness at work. Research in Personnel and Human Resources Management, 30, 115-157.

Goldberg, L. S., \& Grandey, A. A. (2007). Display rules versus display autonomy: Emotion regulation, emotional exhaustion, and task performance in a call center simulation. Journal of Occupational Health Psychology, 12, 301-318.

Grandey, A. A. (2000). Emotion regulation in the workplace: A new way to conceptualize emotional labor. Journal of Occupational Health Psychology, 5, 95-110.

Grandey, A. A. (2003). When "the show must go on": Surface acting and deep acting as determinants of emotional exhaustion and peer-rated service delivery. Academy of Management Journal, 46, 8696.

Grandey, A. A., Dickter, D. N., \& Sin, H. (2004). The customer is not always right: Customer aggression and emotion regulation of service employees. Journal of Organizational Behavior, 25, 397-418. 
Grandey, A. A., Fisk, G. M., \& Steiner, D. D. (2005). Must "service with a smile" be stressful? The moderating role of personal control for American and French employees. Journal of Applied Psychology, 90, 893-904.

Grandey, A. A., \& Gabriel, A. S. (2015). Emotional labor at a crossroads: Where do we go from here? Annual Review of Organizational Psychology and Organizational Behavior, 2, 323-349.

Gross, J. (1998). Antecedent- and response-focused emotion regulation: Divergent consequences for experience, expression, and physiology. Journal of Personality and Social Psychology, 74, 224237.

Hobfoll, S. E. (1989). Conservation of resources: A new attempt at conceptualizing stress. American Psychologist, 44, 513-524.

Hom, P. W., Mitchell, T. R., Lee, T. W., \& Griffeth, R. W. (2012). Reviewing employee turnover: Focusing on proximal withdrawal states and an expanded criterion. Psychological Bulletin, 138, 831-858.

Hülsheger, U. R., \& Schewe, A. F. (2011). On the costs and benefits of emotional labor: A meta-analysis of three decades of research. Journal of Occupational Health Psychology, 16, 361-389.

Jackson, C. L., Colquitt, J. A., Wesson, M. J., \& Zapata-Phelan, C. (2006). Psychological collectivism: A measurement validation and linkage to group member performance. Journal of Applied Psychology, 91, 884-899.

Johnson, H. M., \& Spector, P. E. (2007). Service with a smile: Do emotional intelligence, gender, and autonomy moderate the emotional labor process? Journal of Occupational Health Psychology, 12, 319-333.

Johnson, R., Chang, C.-H., \& Yang, L.-Q. (2010). Commitment and motivation at work: The relevance of employee identity and regulatory focus. Academy of Management Review, 35, 226-245.

Judge, T. A., Erez, A., \& Bono, J. E. (1998). The power of being positive: The relationship between positive self-concept and job performance. Human Performance, 11, 167-187.

Judge, T. A., Erez, A., Bono, J. E., \& Thoresen, C. J. (2003). The Core Self-Evaluations Scale (CSES): Development of a measure. Personnel Psychology, 56, 303-331.

Judge, T. A., Van Vianen, A. E. M., \& De Pater, I. E. (2004). Emotional stability, core self-evaluations, and job outcomes: A review of the evidence and an agenda for future research. Human Performance, 17, 325-346.

Kammeyer-Mueller, J. D., Judge, T. A., \& Scott, B. A. (2009). The role of core self-evaluations in the coping process: Testing an integrative model. Journal of Applied Psychology, 94, 177-195.

Kammeyer-Mueller, J. D., Rubenstein, A. L., Long, D. M., Odio, M. A., Buckman, B. R., Zhang, Y., \& Halvorsen-Ganepola, M. D. K. (2013). A meta-analytic structural model of dispositonal affectivity and emotional labor. Personnel Psychology, 66, 47-90.

Kammeyer-Mueller, J., Simon, L. S., \& Judge, T. A. (2016). A head start or a step behind? Understanding how dispositional and motivational resources influence emotional exhaustion. Journal of Management, 42, 561-581.

Keller, M. M., Chang, M.-L., Becker, E. S., Goetz, T., \& Frenzel, A. C. (2014). Teachers' emotional experiences and exhaustion as predictors of emotional labor in the classroom: An experience sampling study. Frontiers in Psychology, 5, Article ID 1442.

Kristof-Brown, A., Zimmerman, R., \& Johnson, E. (2005). Consequences of individuals' fit at work: A meta-analysis of person-job, person-organization, person-group, and person-supervisor fit. Personnel Psychology, 58, 281-342.

Lazarus, R.S. (1991). Emotion and adaptation. New York: Oxford University Press.

Little, T. D., Cunningham, W. A., Shahar, G., \& Widaman, K. F. (2002). To parcel or not to parcel: Exploring the question, weighing the merits. Structural Equation Modeling, 9, 151-173.

Luchak, A. A., \& Gellatly, I. R. (2007). A comparison of linear and nonlinear relations between organizational commitment and work outcomes. Journal of Applied Psychology, 92, 786-793.

Maslach, C., \& Jackson, S. E. (1981). The measurement of experienced burnout. Journal of Occupational Behaviour, 2, 99-113.

104 Journal of Organizational Psychology Vol. 19(6) 2019 
Maslach, C., \& Jackson, S. E. (1984). Burnout in organizational settings. Applied Social Psychology Annual, 5, 133-153.

Maslach, C., Schaufeli, W. B., \& Leiter, M. P. (2001). Job burnout. Annual Review of Psychology, 52, 397-422.

Melamed, S., Shirom, A., Toker, S., Berliner, S., \& Shapira, I. (2006). Burnout and risk of cardiovascular disease: Evidence, possible causal paths, and promising research directions. Psychological Bulletin, 132, 327-353.

Moller, A. C., Deci, E. L., \& Ryan, R. M. (2006). Choice and ego-depletion: The moderating role of autonomy. Personality \& Social Psychology Bulletin, 32, 1024-1036.

Morris, J. A., \& Feldman, D. C. (1997). Managing emotions in the workplace. Journal of Managerial Issues, 9, 257-274.

Muraven, M., \& Baumeister, R. F. (2000). Self-regulation and depletion of limited resources: Does selfcontrol resemble a muscle? Psychological Bulletin, 126, 247-259.

Muthén, L. K., \& Muthén, B. O. (2012). Mplus user's guide (7th ed.). Los Angeles, CA: Muthén \& Muthén.

Nunnally, J. C. (1978). Psychometric theory (2nd ed.). New York: McGraw-Hill.

Platt, J. R. (1964). Strong inference: Certain systematic methods of scientific thinking may produce much more rapid progress than others. Science, 146, 347-353.

Podsakoff, P. M., MacKenzie, S. B., Lee, J., \& Podsakoff, N. P. (2003). Common method biases in behavioral research: A critical review of the literature and recommended remedies. Journal of Applied Psychology, 88, 879-903.

Pugh, S. D., Groth, M., \& Hennig-Thurau, T. (2011). Willing and able to fake emotions: A closer examination of the link between emotional dissonance and employee well-being. Journal of Applied Psychology, 96, 377-390.

Rupp, D. E., \& Spencer, S. (2006). When customers lash out: The effects of customer interactional injustice on emotional labor and the mediating role of discrete emotions. Journal of Applied Psychology, 91(4), 971-978.

Scott, B. A., \& Barnes, C. M. (2011). A multilevel field investigation of emotional labor, affect, work withdrawal, and gender. Academy of Management Journal, 54, 116-136.

Selig, J. P., \& Preacher, K. J. (2008). Monte Carlo method for assessing mediation: An interactive tool for creating confidence intervals for indirect effects [Computer software]. Retrieved from http://www.quantpsy.org/medmc/medmc.htm

Siemsen, E., Roth, A., \& Oliveira, P. (2010). Common method bias in regression models with linear, quadratic, and interaction effects. Organizational Research Methods, 13, 456-476.

Snijders, T. A. B., \& Bosker, R. (1999). Multilevel analysis: An introduction to basic and advanced multilevel modeling. London: Sage.

Stickney, L. T., \& Geddes, D. (2014). Positive, proactive, and committed: The surprising connection between good citizens and expressed (vs. suppressed) anger at work. Negotiation and Conflict Management Research, 7, 243-264.

Totterdell, P., \& Parkinson, B. (1999). Use and effectiveness of self-regulation strategies for improving mood in a group of trainee teachers. Journal of Occupational Health Psychology, 4, 219-232.

Turner, A. (2019). The World Health Organization officially recognizes workplace "burnout" as an occupational phenomenon. Retrieved at https:/www.cnbc.com/2019/05/28/who-recognizesworkplace-burnout-as-an-occupational-phenomenon.html

Vohs, K. D., \& Heatherton, T. F. (2000). Self-regulatory failure: A resource-depletion approach. Psychological Science, 11, 249-254.

Wagstaff, M. F., del Carmen Triana, M., Kim, S., \& Al-Riyami, S. (2015). Responses to discrimination: Relationships between social support seeking, core self-evaluations, and withdrawal behaviors. Human Resource Management, 54, 673-687. 
Wang, M., Liao, H., Zhan, Y., \& Shi, J. (2011). Daily customer mistreatment and employee sabotage against customers: Examining emotion and resource perspectives. Academy of Management Journal, 54, 312-334.

Watson, D., Clark, L. A., \& Tellegen, A. (1988). Development and validation of brief measures of positive and negative affect: The PANAS scales. Journal of Personality and Social Psychology, 54, 1063-1070.

Wharton, A. S. (1993). The affective consequences of service work: Managing emotions on the job. Work and Occupations: An International Sociological Journal, 20, 205-232. 